\title{
Sistema Vocálico da língua Panará (Jê)
}

Vowel System of Panará Language (Jê)

Eduardo Alves Vasconcelos

Universidade Federal do Amapá ${ }^{1}$

Resumo. Os primeiros estudos fonológicos sobre a língua Panará (Jê setentrional) foram realizados por Dourado $(1990,2001)$. Nessas análises, a pesquisadora propõe três alturas distintivas para as vogais orais e duas para as nasais, totalizando, assim, 15 segmentos vocálicos. Essa proposta é consistente com o padrão observado nas demais línguas Jê e com a proposta de reconstrução de Davis (1966) para essa família. No entanto, os fatos apresentados são pouco conclusivos quanto à distinção do traço [+ baixo] entre as vogais orais anteriores [-post.] e posteriores [+post.]. No corpus resultante de trabalho de campo em 2012, foi possível postular um sistema vocálico composto por sete vogais orais e seis nasais, divergindo da proposta de Dourado $(1990,2001)$, no qual o traço [+baixo] é distintivo somente entre as vogais posteriores não-arredondadas [+post., -arr.] e nas demais posições a oposição se dá somente pelo traço [ \pm alto]. Este estudo tem como foco a discussão do sistema vocálico do Panará a partir da identificação dos traços distintivos relevantes.

Palavras-chave: Línguas Indígenas Brasileiras. Línguas Jê. Panará. Fonologia

Abstract. The first phonological studies about Panará language (Northern Jê) were by Dourado (1990, 2001). In these analyses, the researcher proposes three distinctives heights for oral vowels and two distinctives heights for nasal vowels, thus totalling 15 vowel segments. This proposal is consistent with the pattern observed in the other Jê languages and with Davis' (1966) reconstruction proposal for this language family. However, the facts presented are not conclusive as to the distinction of the feature [+ low] between the previous [-post.] and posterior [+ post.] oral vowels. In the corpus resulting from fieldwork in 2012, it was possible to postulate a vowel system composed of seven oral vowels and six nasal vowels, diverging from Dourado's proposal $(1990,2001)$, in which the feature [+ low] is distinctive only between posterior non-rounded vowels [+ post., -arr.] and in the other positions the opposition occurs only through the feature [ \pm high]. This study focuses on the discussion of the Panará vowel system, based on the identification of the relevant distinctive features.

Keywords: Brazillian Indigenous language. Jê Languages. Panará Language. Phonology.

\section{Introdução}

Os Panará são uma sociedade indígena do Brasil que vive na fronteira entre os estados do Pará e Mato Grosso, com uma população de, aproximadamente, 542 indivíduos (SESAI apud ISA ${ }^{2}$ ). Sua língua, o Panará, pertence a família Jê e foi classificada por Rodrigues (1999) dentro do ramo Jê Setentrional e, mais recentemente, por Nikulin (2019) como pertencente ao ramo Jê SetentrionalPanará e, ainda, por Nikulin \& Salanova (2019) como ramo Jê de Goyaz ${ }^{3}$.Essa língua consta com estudos fonético-fonológicos realizados por Dourado (1990, 2001), Vasconcelos (2013a, 2013b) e,

\footnotetext{
${ }^{1}$ Professor no Programa de Pós-Graduação em Letras (PPGLET/UNIFAP).

${ }^{2}$ Cf. página dedicada aos Panará no site do Instituto Socioambiental: www.pib.sociambiental/pt/Povo:Panará.

${ }^{3}$ Essa classificação é aquela adotada em Nikulin (2020), ao tratar da reconstrução do Proro-Marco-Jê.
} 
ainda, por Lapierre (2016) e Bardagil-Mas (2018). Nesse estudo, será discutida a proposta de sistema vocálico apresentada por Vasconcelos $(2013 b)^{4}$ e suas divergências de Dourado (1990. 2001).

O contato dos Panará com a sociedade não-indígena ocorreu no final da década de 1960, intensificando-se no início dos anos 1970. O contato trouxe uma brusca redução populacional e, quando foram transferidos para o Parque Indígena do Xingu, em 1975, estavam reduzidos a 79 indivíduos. No início da década 1990 iniciaram o processo de retomada de parte do seu território tradicional e, em 1996, a Terra Indígena Panará, na divisa do Mato Grosso com o Pará, foi homologada. Atualmente, os Panará fundaram cinco aldeais, dessas Nasepotíti é a maior e a mais antiga e com maior número de pessoas, construída quando os Panará iniciaram a retomada do seu território tradicional. A cidade mais próxima é Guarantã do Norte (MT).

No trabalho de campo realizado em 2012, a maior parte das gravações foi realizada em Nasepotiti, tendo como principais informantes: Sejakiá, senhor com aproximadamente 60 anos, bilíngue, e Kupere, senhor com aproximadamente 60 anos, também bilíngue. Ainda em Nasepotiti, foram entrevistadas duas senhoras: Wopo, falante monolíngue, com aproximadamente 70 anos, e Krєpa, com pouco domínio do português, com aproximadamente 50 anos. Em Sõkue, entrevistamos Karãpo, senhora bilíngue e com aproximadamente 40 anos. 0 corpus produzido naquele Trabalho de Campo conta com cerca de 900 itens, a maior parte proveniente das gravações com Kupere e Sejakjá.

Nessa análise, a partir deste corpus de 2012, questiona-se a interpretação fonológica dada por Dourado (1990, 2001) ao sistema fonológico da língua Panará.

\section{A proposta de Dourado $(1990,2001)$}

O quadro de vogais proposto em Dourado $(1990,2001)$ é consistente com aqueles encontrados nas demais línguas Jê: nove vogais orais, distinguindo três alturas e seis vogais nasais, com duas alturas. Porém, os exemplos apresentados são pouco conclusivos, principalmente, quanto à distinção de altura entre as vogais orais, como podemos observar nos pares mínimos selecionados pela pesquisadora:

$\begin{array}{llll}\text { (01) } & \text { /ĩte/ 'fino' } & \text { /ĩte/ 'perna' } & \text { (DOURADO, 1990, p. 44) } \\ \text { (02) } & \text { /T'ko/ 'água' } & \text { /ĩkJ/ 'molhado' } & \text { (DOURADO, 1900, p. 45) }\end{array}$

Ou ainda, em variações encontradas na sua tese de doutorado:

(03) kari '2pl.erg' (DOURADO, 2001, p. 28)

(04) pupo 'flecha' (DOURADO, 2001, p. 23) kare '2pl.erg' (DOURADO, 2001, p. 102)

popo 'flechar' (DOURADO, 2001, p. 66)

Acrescenta-se que os itens como (03) e (04) podem ser resultado da interpretação dada aos casos de "overlaping" ou sobreposição, numerosos em sua descrição, como podemos observar na proposta de fonemas vocálicos a seguir. ${ }^{5}$

\footnotetext{
${ }^{4}$ Com algumas alterações, esse texto é parte da tese intitulada Investigando a Hipótese Cayapó do Sul-Panará, de 2013. ${ }^{5}$ Neste quadro foram transliterados os símbolos fonéticos da tradição fonêmica para o Alfabeto Fonético Internacional (IPA).
} 
Quadro 1: Vogais Panará (DOURADO, 1990)

\begin{tabular}{|c|c|c|c|c|c|c|c|c|c|c|}
\hline /i/ & $\begin{array}{l}\mathrm{i}] \\
{[\mathrm{I}]}\end{array}$ & $/ \mathfrak{i} /$ & $\begin{array}{l}\mathrm{i}] \quad / \mathrm{u} / \\
{[\mathrm{Y}]}\end{array}$ & $\begin{array}{l}{[u]} \\
{[v]}\end{array}$ & /ĩ/ & $\begin{array}{l}{[\tilde{i}:]} \\
{[\tilde{I}]} \\
{[\tilde{I}]}\end{array}$ & $/ \tilde{\mathbf{x}}$ & $\begin{array}{l}\tilde{\mathbf{y}}] \\
{[\tilde{Y}]}\end{array}$ & /ũ/ & $\begin{array}{l}{[\tilde{u}]} \\
{[\tilde{\mho}]}\end{array}$ \\
\hline /e/ & $\begin{array}{l}{[\mathrm{e}]} \\
{[\stackrel{\mathrm{e}}{\mathrm{T}}]}\end{array}$ & /ə/ & $\begin{array}{ll}\text { [ə:] } & / \text { / } \\
{[ə]} & \\
{[\wedge]} & \end{array}$ & $\begin{array}{l}{[\mho]} \\
{[0]} \\
{[0]}\end{array}$ & /ẽ/ & $\begin{array}{l}{[\tilde{e}]} \\
{[\tilde{\varepsilon}:]} \\
{[\tilde{\varepsilon}]}\end{array}$ & /ã/ & $\begin{array}{l}{[\tilde{a}]} \\
{[\tilde{\partial}:]} \\
{[\tilde{a} \tilde{a}]} \\
{[\tilde{\Lambda}:]}\end{array}$ & /õ/ & $\begin{array}{l}{[\tilde{0}]} \\
{[\tilde{0}]} \\
{[\tilde{0}:]} \\
{[\tilde{0}]}\end{array}$ \\
\hline $\mid \varepsilon /$ & $\begin{array}{l}\text { [ẹ] } \\
{[\varepsilon]} \\
{[\varepsilon]} \\
{[æ]}\end{array}$ & $|a|$ & $\begin{array}{ll}{[\Lambda]} & / \mathrm{J} / \\
{[\mathrm{a}]} & \\
{[\mathrm{a}:]} & \\
\text { [a] } & \\
\text { [a:] } & \\
\text { [a] } & \end{array}$ & $\begin{array}{l}\text { [o] } \\
\text { [ગ] } \\
\text { [ָ] } \\
\text { [a] }\end{array}$ & & & & $\begin{array}{l}{[\tilde{n}]} \\
{[\tilde{a}:]} \\
{[\tilde{a}]} \\
{[a ̣:]} \\
\text { [ạ] }\end{array}$ & & [व̃] \\
\hline
\end{tabular}

Sobre os casos de "overlaping" ou sobreposição, a autora explica que: "o critério para atribuir estes fones a um, ou a outro fonema, foi o da alternância dos fones entre si. Isto é, quando [U] ${ }^{6}$ alterna com [u] é considerado alofone de /u/, e quando alterna com [o] é considerado alofone de /o/" (DOURADO, 1990, p. 53). Este critério também foi adotado em casos semelhantes entre as consoantes, em que, por exemplo, [r] ora figura como alofone de /n/ ora como de /r/.

Em Vasconcelos (2013a), foi realizada uma primeira revisão da interpretação fonológica proposta por Dourado (1990, 2001), em que foram utilizados somente os dados disponíveis nas análises da pesquisadora. Por conta da fragilidade das oposições entre as vogais, sugeriu-se que, considerando a proposta de Davis (1966) para o Proto-Jê, "el Panará podría haber simplificado el sistema vocálico en las vocales orales". Nessa simplificação, das nove vogais da proto-língua, o Panará passaria a seis, mesmo número de vocais nasais. Naquele mesmo texto, o autor acrescentou que:

La comparación con el léxico de otras lenguas Jê permite sugerir que, si se confirmara la simplificación del sistema vocálico oral de los Panará, ésta podría haber sucedido de la siguiente forma:

i. las realizaciones $[e]$ y $[\varepsilon]$ se fundieron en un único fonema. Tal vez algunas [e] hayan pasado a $[ə]$ o $/ \mathrm{i} / ;$

ii. las realizaciones [o] y [0] se fundieron en un único fonema; sin embargo, puede ser que un grupo de palabras con [o] pasaran a usar el fonema /u/;

iii. las realizaciones $[\dagger]$ e $[ə]$ se fundieron en un único fonema.

Alternativamente a lo sugerido en (iii), podría haber ocurrido (iv) y (v):

iv. las realizaciones [ə] pasaron para [a];

v. las realizaciones [a] (o parte de ellas) pasaron para [ã].

Ainda em Vasconcelos (2013a), foram questionadas as sequências de vogais e as sequências vogais-glides, pois "el análisis fonológico de la autora [DOURADO, 1990] hace que se interpretan todos los casos como secuencias heterossilábicas de vocales idênticas se dan com /i/, /u/ y /a/, y com /î/, /ũ/ y /ã/" (VASCONCELOS, 2013a, p. 150). No caso das tautossilábicas, foram analisadas como "secuencias de vocal con consonante (en esa última posición, las aproximantes /j/ y /w/)"

\footnotetext{
${ }^{6}[\mho]$ em IPA.
} 
(VASCONCELOS, 2013a, p. 150). Foram apontadas as seguintes inconsistências nos dados disponíveis: (i) how ow (DOURADO, 2002, p.216); (ii) $\eta k o \sim k o=$ água $\sim k o w=$ rio (DOURADO, 1990, p. 12; DOURADO, 2001, p. 93 e 45). Como se tratava de uma primeira revisão da, então, única análise fonológica para a língua Panará, apontou-se que as sequências vocálicas e os possíveis ditongos necessitavam de uma investigação mais aprofundada.

\section{Considerações fonéticas}

Antes de apresentar os fones vocálicos, faz-se necessário fazer um breve comentário a duas características comuns às vogais do Panará: alongamento vocálico e aspiração vocálica em sílaba final. $O$ alongamento vocálico pode ser identificado como duração ou pela presença de [j] após vogal anterior e [w] após vogal posterior. Em Dourado $(1990,2001)$, as aproximantes foram tratadas como soantes em coda silábica. Já em Vasconcelos (2013a, p. 156), apontava-se o caráter fonético dessas realizações. Nesta análise se mantém a proposta de que as aproximantes estão marcando duração vocálica, como podemos observar nos itens seguintes:

(5) a. [ĩko 'k'krẽ] 'coração'

b. [ĩ'kjpw] ['kjəw] 'não'

c. [kJw'pasə] [kJ'pasə] 'borduna'

d. [powpa'sə] [pope'sə] 'poraquê'

e. [sẽj'si] 'grosso' f. [nãnk̂kokrz̃tu'sə:] 'coração batendo'

g. [tow'toke] [to'toke] 'macaco (tipo)'

h. [tawmã'prə] [towmã'mprə] 'amarelo'

i. [i?,ko] [i'kow] 'macaco'

j. [pĩje'se:ri:] [pĩje'sejri] 'brincadeira'

Ainda não foi possível estabelecer as motivações de todas as realizações das vogais longas. Uma hipótese é que tais ocorrências estejam relacionadas à prosódia do Panará. O que se observou no trabalho de campo é que uma vogal pode ser alongada para dar ênfase a uma característica, assim, [kĩ] pode ser traduzido como 'bonito' e [kĩ: putẽ'si] como 'muito bonito mesmo'. A duração não seria distintiva como podemos observar nos itens seguintes?

(6)
a. [si:kre'ko] [sikre'ko] 'furo da orelha'
b. [kwa,tĩ:'te:pi] 'fruto da mata'
c. [pəri'te:] [pəri'te] 'pau fino'
d. [te:p] [tep] 'peixe'
e. [pə:'ri] [pə'ri] 'árvore, pau'
f. [kəje,sə'pə̃:] [kəje,sə'pã] 'faca'
g. [sa:'se] [sa'se] 'rede'
h. [pu:'su] [pu'su] 'muriçoca'
i. [kjo:ri'ti] [kjori'ti] 'caititu'
j. [ps:'kə] 'nome próprio'
h. ['to:tř] ['tot] 'cesto'

i. ['kĩ:] [kĩ] 'bonito'

j. [se:'kə] [se' $\left.{ }^{h} k ə\right]$ 'cueca'

k. [sə'pe:ri] [sə'peri] 'vento'

I. ['ki:pa] 'terra', [kipa'rĩ] 'terra seca'

m. ['kə:] ['kəə] ['kə] 'comprido'

n. [kjã:po] [kjãpo] 'beiju'

o. [pa:'kə] [paa'kə] 'chinelo'

p. [ku:'ku:t'] [ku'kut] 'abóbora'

q. [so'po:we] [so'powe] 'cacau do mato'

r. [tõ:] [tõ] 'outro'

s. [pi'ko:mã] [pi'komã] 'amanhã'

Já as ocorrências de vogais aspiradas podem ser divididas entre aquelas que ocorrem diante de silêncio (7) e aquelas que ocorrem em sílaba não final átona (8). Propõe-se que se trata de

\footnotetext{
${ }^{7}$ Lapierre (2016) e Bardagil-Mas (2018) identificam, a partir de análises acústicas, uma série de vogais longas (orais e nasais) distintivas em Panará. Além disso, Carvalho (2016) propõe que "the rhotic attested in other Northern Jê Languages corresponds to $\varnothing$, not j, in Panará" (p. 65). E essa correspondência se daria justamente em coda: Panará puu 'roça', Mebengokre puru, Apinajé pur, Timbira pur e Suyá hur (Cf. CARVALHO, 2016, p. 65).
} 
variação fonética, no caso da aspiração diante de silêncio como consequência da coleta de dados elicitados, em que os informantes enfatizam a vogal final do termo.

(7) Vogais aspiradas diante de silêncio
a. [nõsu'ti' $]$ [nãsu'ti] 'estrelas'
j. [pəti'ti'] [pəti'ti] 'tamanduá'
b. $\left[\tilde{I}^{\top} \mathrm{t} \varepsilon^{\mathrm{h}}\right] \sim[$ ['t $\varepsilon]$ 'perna'

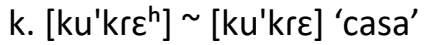
c. $\left[\tilde{I}^{\top} s \dot{s}^{\mathrm{h}}\right] \sim\left[\mathrm{I}^{\top} \mathrm{s} \dot{\mathrm{j}}\right]$ 'semente'
I. [mõ'si' ${ }^{\text {h }}$ [mõ'si] 'milho'
e. [sũ'piə⿳亠丷厂 $]$ [sũ'pjə] 'pai (dele)'
m. ['kuit'] ['kui:.] 'mandioca'
f. ['soah] ['soa] 'dente'
n. $\left[i^{\top} k a^{\mathrm{h}}\right] \sim$ [i'ka] 'tossir'
g. [i'tu'] [i'tu] 'batata'
o. ['puu $\left.{ }^{\text {h}}\right] \sim$ ['puu] 'roça'
h. [nã'po'] [nã'po] 'besouro'
p. [nã'so'] [nã'so] 'rato'
i. [I'kjo $\left.{ }^{\mathrm{h}}\right] \sim$ [î'kjo] 'fedido'
q. ['po $\left.{ }^{\mathrm{h}}\right] \sim\left[\right.$ [po $\left.^{\mathrm{h}}\right] \sim[\mathrm{po}]$ 'flecha (tipo)'

(8) Vogais aspiradas em sílaba não final
a. [titi' 'ti] [titi'ti] 'tatu'
e. [ñ̃ ${ }^{\text {h'pjə] } ~ ~ ~[n ว ̃ ' p j ə] ~ ' m a ̃ e ' ~}$
b. [kwa $\left.{ }^{\text {' }} \mathrm{kjã}\right] ~ ~[k w a ' k j \tilde{z}]$ 'fruto da mata'
f. [ka ${ }^{h}$ 'kre] 'você planta'

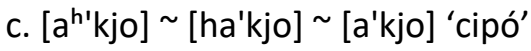

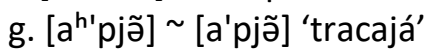
d. [po $\left.{ }^{\mathrm{h}} \mathrm{so}^{\prime} w \mathrm{wa}^{\mathrm{h}}\right]$ 'nome próprio'
h. [su'tîn] [su'tĩ] 'pesado'

Os fones vocálicos registrado no corpus foram:

Quadro 2: Fones vocálicos do Panará (VASCONCELOS, 2013b)

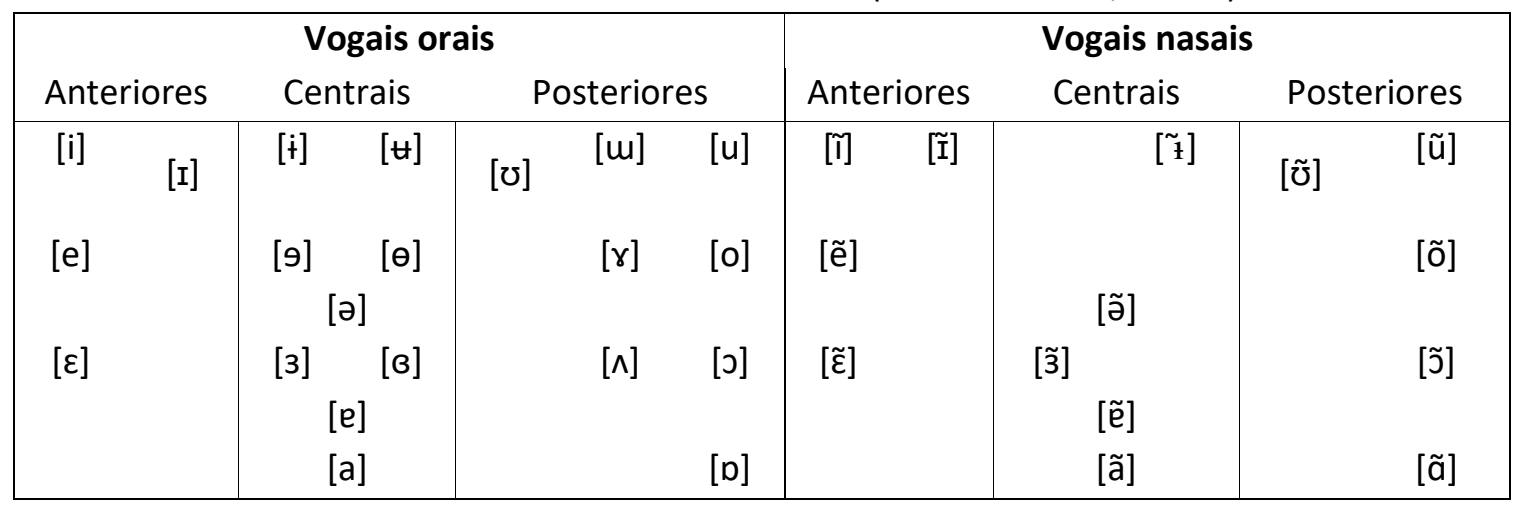

\section{Discussão do quadro e as vogais orais}

Dentre esses fones, a vogal anterior [I] varia com a vogal [i] em sílaba átona: [a'kri' $]$ [ha'kri $\left.{ }^{\text {h }}\right] \sim$ [ha'krr] 'capim, mato', tal variação também é registrada em sílabas átonas formadas a partir da inserção de vogais em coda, como em: [i'kjiti] $~\left[i^{\prime} k j \mathrm{tij}\right] \sim$ [i'kjjtr] [i'kjtt'] [i'kjit] 'anta'. Nas vogais

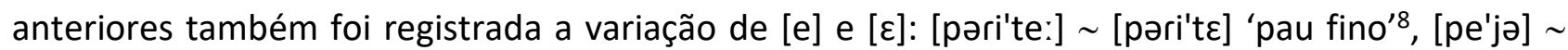
[pe'jə $\left.{ }^{\text {h}}\right] \sim\left[p \varepsilon^{\prime} j \partial^{\text {h] }}\right.$ 'açaí' e [prepa'sə] [prepa'sə] 'formiga'. Tais ocorrências sugerem, diferentemente do que propôs Dourado $(1990,2001)$, que não há oposição entre [e] e [ع]. Também não foram encontrados pares opositivos entre estes segmentos.

A vogal $[t]$ apresenta somente uma ocorrência, em [kə't $t$ ] 'preto', e propõe-se que tanto

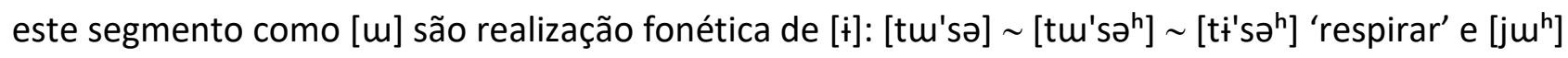

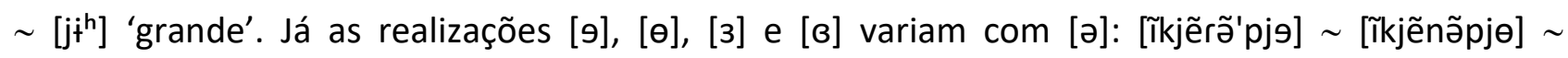

\footnotetext{
${ }^{8}$ No corpus, mesmo termo para cachimbo e cigarro. Dourado (2001) registra um termo próprio para cigarro, distinto de cachimbo.
} 
[ĩkjẽnãpjə] 'minha mãe', [pэrãko] [pərẽ'ko] 'remédio', [pөri'kjə] [pəri'kjə] 'fruta', [kəja'sз]

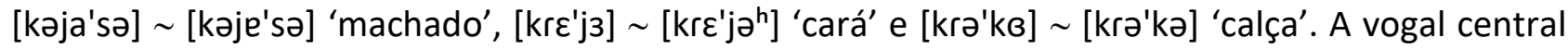
[ə] varia, ainda, com [r]: [prrã'ko] 'suco' (cf. 'remédio'), ['srri] ['səri] 'assado'. Já a vogal [e] ocorre em sílaba átona, pré e pós-tônica, variando com a vogal [a]: [ĩ'kjare] [î'kjara] 'mulher', [mãrejõ'pã] [mãrajõ'pã] 'filho dele' e [koti,tekjã'po] 'jacu'.

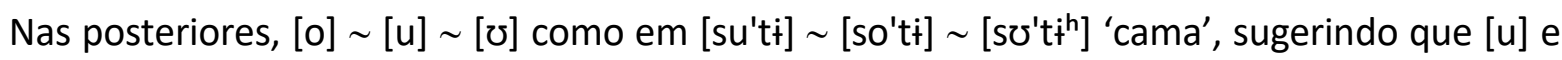
[o] sejam realizações fonéticas de um único fonema. Para melhor compreendermos as oposições nas posteriores, é preciso considerar as variações envolvendo [0], [D] e [ $\Lambda$ ], representada nos seguintes

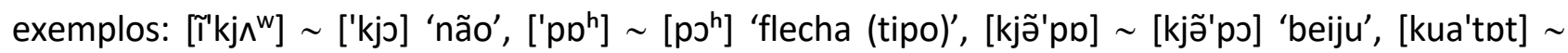
[kua'tıt] [kua'totij] 'sapo', [ĩ,to'so] [ĩ,to'so] 'sobrancelha', ['jpp] ['jjp] 'cachorro, onça' e [tbw'tbke] $\sim$ [to'tıke] 'macaco (mico)'. Observe que as realizações de [0] e [o] estão em variação livre. Quanto à oposição entre as posteriores é preciso considerar os seguintes pares: [kro'kro] 'pássaro (tipo)' $x$

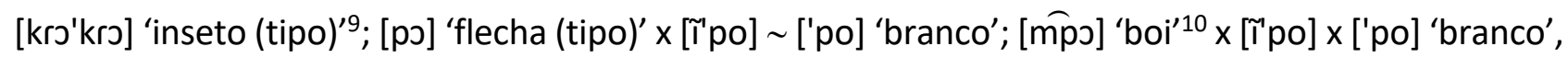
[nã'kjo] [rã'kjo] 'queixada' x [nã'kjo] [rã'kjo] 'quente'. Conferir também: [puu] [pu] 'roça' x ['po] 'flecha (tipo)', ['tu] 'batata' x [a'to] 'pássaro (tipo)'. Tal como para as vogais [-post.], aqui também não há uma distinção entre vogais médias [o] x [0] e, sim, entre $/ \mathrm{u} / \mathrm{x} / \mathrm{J} /$, em que tanto [o] quanto [ひ] são variantes da posterior alta, divergindo, assim, da proposta de Dourado (1990, 2001), que defendia uma oposição entre $/ \mathrm{u} / \mathrm{x} / \mathrm{o} / \mathrm{x} / \mathrm{\jmath} /$.

Se nas posteriores a oposição é entre $/ u / x / \supset /$, entre as vogais anteriores a oposição seria entre $/ \mathrm{i} / \mathrm{x} / \mathrm{e} /$ ou entre $/ \mathrm{i} / \mathrm{x} / \varepsilon /$ ? A oposição que há tanto nas anteriores quanto nas posteriores é entre o traço [+ alto]: /i u/ e [- alto] / $\varepsilon$ J/. Os demais traços opositivos entre as vogais orais são [ \pm posterior] - /i e/ [-posterior], / + ə u J/ [+posterior] - e, nas posteriores, [ \pm arredondado] - / + ə/ [arredondado] /u o/ [+ arredondado]. A vogal [a], especificada com o traço [+ baixo], completa os fonemas vocálicos.

Quadro 3: Vogais orais em Panará (VASCONCELOS, 2013b)

\begin{tabular}{|cccc|}
\hline & [-posterior] & \multicolumn{2}{c|}{$[$ [+ posterior] } \\
& & {$[$-arr] } & {$[+$ arr] } \\
[+alto] & $/ \mathrm{i} /$ & $/ \mathrm{i} /$ & $/ \mathrm{u} /$ \\
[-alto] & $/ \varepsilon /$ & $/ \mathrm{J} /$ & $/ \mathrm{J} /$ \\
[+baixo] & & $/ \mathrm{a} /$ & \\
\hline
\end{tabular}

Os itens (9-27) ilustram as oposições identificadas entre as vogais orais.

\footnotetext{
${ }^{9}$ Inseto utilizado como isca para pesca.

${ }^{10}$ Termo utilizado também para cavalo.
} 
(i) [+alto] x [-alto]

/i/ $x / \varepsilon /$

(9) a. ['si] /'si/ 'osso'

b. [i?'se] /ih'sc/ 'cera de abelha'

(10) a. [kri] /'kri/ 'aldeia'

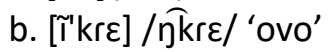

(11) a. [ti] /ti/ 'pron. 3a pessoa'11

b. ['tc] /'t $\varepsilon /$ 'perna'

/ít x /ə/

(12) a. [jã'si்] /jã'si்/ 'veado'

b. [jõ'sə] /jõ'sə/ 'tucano'

(13) a. [sं] /'st/ 'semente'

b. [a'sət] x [a'sətị] /a'sət/ 'algodão'

/u/ x / /

(14) a. [pu] [puu] /'puu/ 'roça'

b. ['po'] ['pp] /'po/ 'flecha (tipo)'

(15) a. [kro'kro] /kru'kru/ 'pássaro (tipo)'

b. [kro'kro] /kro'kro/ 'inseto (tipo)'

(ii) [-posterior] $x$ [+posterior]

/i/ $x$ /it/

(16) a. ['si] /'si/ 'osso'

b. [si] /'sì/ 'semente'

(17) a. [jo'ti] /jo'ti/ 'sucuri'

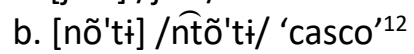

/i/ $x$ /u/

(18) a. ['kiti] ['kid] /'kit/ 'pequeno'13

b. [ku'kut] [ku'kuti] /ku'kut/ 'abóbora'
/ع/ x /ə/

(19) a. [î'se] [î'tse] /'ñ̂s / 'arco'

b. ['sə] /'sə/ 'gavião'

(20) a. [nã'pe] [nẽ'pe] /ñ̃̃'ps/ 'açai'

b. [ñ̃'mp̃] /ntว̃'mp̃/ 'arara'

$/ \varepsilon / x / \jmath /$

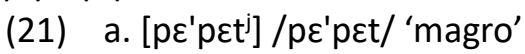

b. [po'pot] /po'pot/ 'baixo'

(iii) [- arredondado] $\mathrm{x}$ [+ arredondado] /it $x / \mathrm{u} /$

(22) a. ['pi] /'pit 'urucum'

b. [pu] [puu] /puu/ 'roça'

(23) a. [î'ttit]/' $\widehat{n t} \dot{t} /$ 'capivara'

b. [i'tu] [hi'tu] /hi'tu/ 'batata'

/ə/ $x / \mathrm{J} /$

(24) a. [pə̃'kJ] /pã'kJ/ 'gavião'

b. [pẽ'kə] /pẽ'kə/ 'vestido'

(25) a. ['tət'i] /'tət/ 'forte'

b. ['tot] /tot/ 'estampido'

(iv) [+baixo]

/a/ $x$ /ə/

(26) a. [ka] /ka/ 'pron. 2a pessoa'14

b. ['kə] /'kə/ 'couro'

(27) a. [nã'ka] [rã'ka] /rã'ka/ 'feio'

b. [ñ̃'kə] [rã'kə] /rã'kə/ 'cobra'

\section{Vogais Nasais}

A oposição básica entre as vogais é oral vs. nasal. As demais oposições são pelos traços [ \pm posterior],

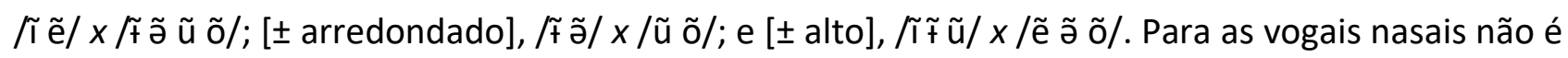
relevante o traço [ \pm baixo], que nas vogais orais permitia a oposição de /a/ às demais vogais.

Sobre os fones nasais, só há uma única ocorrência no corpus da posterior [च̃], em [ñ̃'ka]

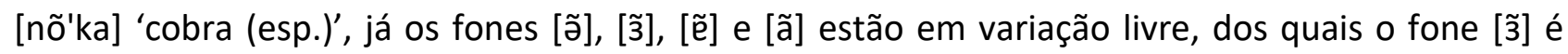

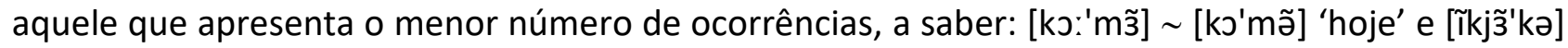
$\sim$ [ĩkjã'kə] [kjã'kə] 'casca'.

\footnotetext{
${ }^{11}$ Seguindo a proposta de tradução em Dourado (2001).

${ }^{12}$ No sistema consonantal do Panará é preciso investigar o critério para identificar se uma realização nasal é resultado da nasalização de um [r] ou de uma pré-nasalizada [ $\widehat{n t}$ ]. Preliminarmente, optou-se pelo critério de variação, porém, não se descarta que diante de vogal nasal há um processo de neutralização de [r] e [ $\widehat{n} \widehat{t}]$, ponto ainda a ser investigado. 13 [se'kid] 'arco pequeno' e ['kitị] 'cesto pequeno'.

${ }^{14}$ Seguindo proposta de Dourado (2001).
} 
Quadro 4: Vogais nasais em Panará (VASCONCELOS, 2013b)

\begin{tabular}{|cccc|}
\hline & [-posterior $]$ & \multicolumn{2}{c|}{ [+ posterior] } \\
& & {$[$ [-arr $]$} & {$[+$ arr $]$} \\
[+alto] & $/ \tilde{l} /$ & $/ \tilde{t} /$ & $/ \tilde{u} /$ \\
{$[$-alto $]$} & $/ \tilde{e} /$ & $/ \tilde{a} /$ & $/ \tilde{o} /$ \\
\hline
\end{tabular}

Os exemplos a seguir ilustram as oposições entre as vogais nasais:

(i) [+alto] $\times$ [-alto]

/ĩ $x / \tilde{e} /$

(28) a. ['pĩ] /'pĩ/ 'lenha'

b. ['pẽn] /'pẽr/ 'falar'

(29) a. [mĩ] /'mpĩ/ 'jacaré'

b. [mẽ] /'mpẽ/ 'e' (DOURADO, 2001)

$/ \tilde{t} / x / \tilde{\partial} /$

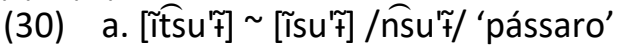

b. [suã'pro] /swã'pro/ 'beiju aberto'

/ũ/ $x / \tilde{o} /$

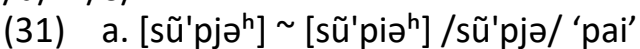

b. [sõ'pã] /sõ'pã/ 'filho'

(32) a. ['pũ] /'pũ/ 'ver'

b. [põ'põ] /põ'põ/ 'pássaro (inhambu)'

(ii) [-posterior] $x$ [+posterior]

$/ \tilde{\mathrm{i}} / \mathrm{x} / \tilde{\mathrm{t}} /$

(33) a. ['sĩ] /'sĩ/ 'pele'

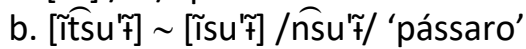

/ĩ $x / \tilde{u} /$

(34) a. ['pĩ] /'pĩ/ 'lenha'

b. ['pũ] /'pũ/ 'ver' /ẽ/ $x / \tilde{\text { õ }}$

(35) a. [kjẽ'po] /kjẽ'po/ 'pedra de amolar'

b. [kjã'po] /kjã'po/ 'beiju'

(36) a. [ju'tẽn] /ju'tẽr/ 'cair'

b. [ju'tã] /ju'tõ/ 'longe'

/ẽ/ $x / \tilde{o} /$

(37) a. [sẽ̃'si] /sẽ'si/ 'grosso'

b. [sõ'se] /sõ'se/ 'aranha'

(38) a. [tõ'tõja]/tõ'tõja/ 'cachorro do mato'

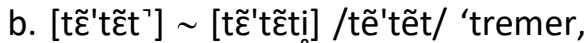
tremedeira'

(iii) [- arredondado] $x[+$ arredondado]

$/ \tilde{\mathrm{t}} / x / \mathrm{u} /$

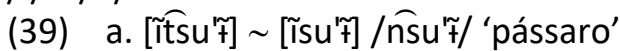

b. [sũ'pjə⿳亠丷厂 $] \sim[$ sũ'piə⿳亠口冋 $] /$ sũ'pjə/ 'pai'

/כ̃/ $x / \tilde{o} /$

(40) a. [pã'pã] /pã'pã/ 'todos'

b. [рõ'põ] /põ'põ/ 'pássaro (inhambu)'

(41)

a. [nว̃'ka] [rã'ka] 'feio'

b. [nõ'ka] /rõ'ka/ 'cobra (jararaca)'

Nos itens seguintes é apresentada a oposição oral x nasal.

/i/ $\times / \tilde{i} /$

(42) a. ['si] /'si/ 'osso'

b. ['sĩ] /'sĩ/ 'pele'

(43) a. [saa'si] /saa'si/ 'asa'

b. [sa'sĩ] /sa'sĩ/ 'nariz'

$/ \varepsilon / x / \tilde{e} /$

(44) a. ['t $\varepsilon] /$ 't $\varepsilon /$ 'perna'

b. [ju'tẽnn]/ju'tẽr/ 'cair'

(45) a. [pe'ja] /pe'ja/ 'açaí'

b. [pẽ'kə] /pẽ'kə/ 'roupa'

$/ \mathfrak{t} / x / \tilde{t} /$

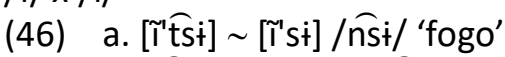

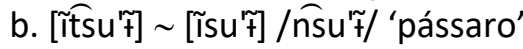

/ə/ x/כ̃/

(47) a. ['kə]/'kə/

b. [kãn] [kã] /'kãr/ 'cesto'

(48) a. [î'ta] [ ['ntah ] /'nta/ 'chuva'

b. ['tã] /'tã/ 'alativo' (DOURADO, 2001)

$/ \mathrm{u} / x / \tilde{u} /$

(49) a. [pu] [puu] /puu/ 'roça'

b.['pũ] /'pũ/ 'ver'

(50) a. [i'tu] /i'tu/ 'batata'

b. [tũ'mã] /tũ'mp̃̃̃/'gordura'

/ว/ $x / \tilde{o} /$

(51) a. [î'to] [' $\widehat{n t o}] /$ 'ntว/ 'olho'

b. ['tõ] /'tõ/ 'irmão'

(52) a. [î́p ] [mps] /'mp̃/ 'boi'

b. [mõ'sì] /mpõ'sì/ 'milho' 


\section{Considerações Finais}

Nesta proposta de análise, o sistema vocálico do Panará tem um número de vogais reduzido em comparação ao proposto por Dourado (1990, 2001). Na interpretação da pesquisadora são distinguíveis nove vogais orais, com três alturas entre anteriores [-post.] e nas posteriores [+post. \pm arr.], enquanto propomos um sistema com sete vogais orais, com o traço [baixo] restrito às vogais [+post. -arr.]. Sobre as vogais nasais, particularmente, é preciso avaliar se a oposição [ \pm alto] para as posteriores não-arredondadas é relevante ou se ela foi neutralizada, tal suspeita é gerada pelo reduzido número de itens em que encontramos a vogal nasal [̃] e, ainda, um caso de variação entre

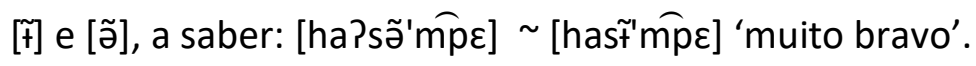

Bardagil-Mas (2018), além da oposição oral x nasal, propõe uma oposição por duração vocálica e, seguindo Dourado (1990, 2001), mantém três alturas vocálicas entre as vogais orais. Dessa forma, em sua análise, "Panará has a total of 29 contrastive vowels, which can be either oral or nasal, and short or long" (BARDAGIL-MAS, 2018, p. 21). Além de propor uma oposição por duração, o pesquisador identifica um fonema / $\mathrm{m} /$, tratado por Dourado $(1990,2001$ ) e por Vasconcelos (2013b) como uma variação de /ł/.

Por fim, em Vasconcelos (2013b), foi proposto para o Panará que a oposição básica das consoantes seria entre obstruintes vs. soantes, enquanto, para as vogais, é entre oral vs. nasal. Nessa proposta, obstruintes e vogais especificadas para SP, com [nasal] marcado somente nas vogais, enquanto as soantes são especificadas para SV, com a implementação da nasalidade nas descontínuas por meio da implementação fonética [Abaixar VP]. Nas consoantes, os traços descontínuo vs. contínuo e grave vs. agudo são secundários, estabelecendo as restrições em clusters e, especificamente grave vs. agudo, licenciando os segmentos em coda (cf. VASCONCELOS, 2013b).

Seguindo a proposta de traços de Jakobson, Fant \& Halle (1952), a oposição básica entre as

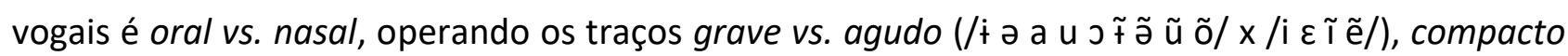
vs. difuso (/i † u ĩ̃ ũ/x / $\varepsilon$ ə a ว ẽ ã õ/); nas graves é preciso distinguir flat vs. plain (/u ว ũ õ/ x /† ə a $\tilde{\partial} /$ ) e, por fim, somente nas orais, tense vs. lax (/i + ə $u / x / \varepsilon$ a $\supset /)$.

\section{Referências}

BARDAGIL-MAS, B. Case and agreement in Panará. LOT: Netherlands Graduate School, 2018.

CARVALHO, F. O. On the development of the Proto-Northern-Jê rhotic in Panará historical phonology. Anthropological Linguistics, Lincoln, v. 58, n. 1, p. 52-78, 2016.

DAVIS, I. Comparative Jê phonology. Estudos Lingüísticos: Revista Brasileira de Lingüística Teórica e Aplicada, São Paulo, v. 1, n. 2, p. 20-24, 1966.

DOURADO, L. Estudo preliminar da fonêmica Panará. 1990. Dissertação (Mestrado em Linguística) - Instituto de Letras, Universidade de Brasília, Brasília, 1990.

DOURADO, L. Aspectos Morfossintáticos da Língua Panará (Jê). Tese (Doutorado em Linguística) Instituto de Estudos da Linguagem, Universidade Estadual de Campinas, Campinas, 2001. 
LAPIERRE, M. Predicting Vowel Systems: an Acoustic Analysis of the Vowels of Mebêngôkre and Panará. In: Proceedings of the Annual Meetings on Phonology, vol. 03, 2016.

NIKULIN, A. A reconstruction of Proto-Jê phonology and lexicon. Journal of Language Relationship, Moscou, v. 17, n. 2, p. 93-127, 2019.

NIKULIN, A.; SALANOVA, A. P. Northern Jê verb morphology and the reconstruction of finiteness alternations. International Journal of American Linguistics, Chicago, v. 85, n. 4, p. 533-567, 2019.

NIKULIN, A. Proto-Macro-Jê: um estudo reconstrutivo. 2020. Tese (Doutorado em Linguística) Instituto de Letras, Universidade de Brasília, Brasília, 2020.

RODRIGUES, A. D. Macro-Jê. In DIXON, R.M.W.; Aikhenvald, A.Y. (Orgs.). The Amazonian Languages. Cambridge: Cambridge University Press, 1999, p.164-206.

VASCONCELOS, E. A. Repensando la Fonologia de la Lengua Panará (Jê). In: BOMBELLI, G.; SOLER, L. Oralidad. Miradas plurilingües desde la fonética y la fonología. Córdoba, AR: Buena Vista Editores, 2013a.

VASCONCELOS, E. A. Investigando a hipótese Cayapó do Sul-Panará. 2013. Tese (Doutorado em Linguística) - Instituto de Estudos da Linguagem, Universidade Estadual de Campinas, Campinas, 2013b. 